\title{
A Consideration of Reciprocity: The Kantian and Hegelian Treatments
}

ROBERT VAN RODEN ALLEN

Pennsylvania State University

In order to understand the Hegelian project, its "immanent" development and its appropriation of philosophical systems before it, it is necessary for us to carry out a constant process of comparing and contrasting what Hegel attempts with what other philosophers had attempted. As one works through the second major division of Hegel's Logic, the shadow of the Kantian system is ever present. Most obviously this is the case as Hegel considers and rearranges the various categories which had been crucial for Kant. However, since Hegel will not only manipulate for his own purposes and follow out the development of such categories, but will also go beyond them, a reconsideration of his claims will profit from a comparison with the Kantian system. Thus, I intend to review what seem crucial aspects, implicit or explicit, of Kant's first Critique as they apply to the materials with which Hegel ends his consideration of "Essence," especially in order to see what happens to Kantian reciprocity at the hands of Hegel.

We must first recall a few salient points of the Kantian system. Through the discovery of the transcendental unity of apperception, Kant explores as fully as he thinks possible the regressive eplstemic movement. He claims this movement to be self-limiting and inherently capable of avoiding the metaphysical trap of an infinite regression which could only yield scepticism about any knowing whatsoever. This limit encountered is the transparency or non-solidity of the transcendental unity of apperception. It defines what is within our grasp. Kant is not tempted by the need or necessity of going beyond that limit if we are unable. He avoids the old metaphysical trap of ontological principles and concepts.

Through the Critique we have learned of reason's temptation or propensity toward transcendent transgression. Already, we may anticipate that what Kant construes as a limit to knowing and therefore as a more solid, well-clarified, because delimited, aspect of the 
known, Hegel will seize upon as the mere, impotent limitation upon our knowing, assuming us to be capable of much more. In the ultimate sense, any Kantian "find" will remain for Hegel a usual proposition, a partial truth or aspect of the true speculative proposition. Usual propositions deal with limits which are simply truncated partializations; they assume foundations, as well, which themselves need grounding, establishing the movement of a bad infinite. Only the true movement of the speculative proposition provides any escape from such a quandry. We must keep this in mind, throughout; it wili be especially crucial to Hegel's move "beyond" reciprocity.

Yet, for Kant knowing is limited through and related to experience. Forms of knowing may not need experience in any sense of being determined by experience but will always bear relation to and with experience. Knowing and experiencing are always situated together. Kant consistently emphasizes this point:

We can, however, with regard to these concepts, as with regard to all knowledge, seek to discover in experience, if not the principle of their possibility, at least the occasioning causes of their production."

Kant's stress upon Gelegenheitsursachen, translated somewhat overdeterminateiy as "occasioning causes," would point to experience as the "favorable, nurturing moment and ground" of and for the production of concepts in particular, and of knowledge in general. This is to stress the sense in which Kant sees knowledge and experience, each delimited in certain respects, nonetheless crucially growing up together. If there is to be metaphysical knowledge not arising from experience, it will be nonetheless restricted to and with it. ${ }^{2}$ How might we understand this in relation to the Hegelian system?

Hyppolite has attempted to elucidate aspects of the Hegelian system by speaking of the relationship of nature to logos. He takes spirit for Hegel. to be the mutual reflecting, intershadowing, reciprocity of these two. They are related in the special sense that:

One should not say Word and Nature, but rather Word is Nature, Nature is Word. Judgment (Urteil) brings to the surface the originary division, it is relative identity, mediation still unmediated. It is only reason, as mediation, which develops the dialectical character of this ig, by showing at the same time, the opposition Of terms, their contradiction, and their identity. Reason alone makes spirit appear within Word and Nature.' 
As Hyppolite notes, with Hegel one does not properly "say" nature and logos. Rather, "nature is logos" is to be said. Such an "and" for Hegel would remain a connection of mere externality; thus, one only properly speaks of the "is," the level of identity which relates them. Yet, for Kant, we see that such an "and" of mere external relation is insufficient as well. But against Hege1, the Kantian claim is that the "is" linking nature and logos (word) 1 s too strong. This is to say that for Kant, nature and logos, experience and concept are together to the degree that they always grow up together. Yet, as different levels of interrelated givenness, they cannot be completely identified. They maintain at the heart of their internal relatedness a certain reciprocal resistance toward each other. Logos is not completely, merely, nature. Nature is not fully sayable (logos). Interrogating the relationship of concepts to experience, in experience, may not yield the principle of their possibility. Yet, it can give us a perspective on the generation or production of such concepts in relation to experience.

Although it may be argued that in the first Critique Kant merely pursues such a perspective, thus more explicitly dealing with the "logos" side alone; the sayability of nature, it is clear that the very pursuit of such a perspective depends on the status of a subjectivity which is the tension of logos-nature. Most clearly seen in the practical philosophy, but ever present in the theoretical as well, is this tension point which is the spontaneous, generative transcendental. unity of apperception, which is participant-speaker in and with logos, which is observer and element in and with nature. The Kantian doctrine concerns the is and the and of the relationship nature/logos, their internal relation and mutual self-limiting and resistance. Such a doctrine claims only to discover levels of relationship, resistance, and givenness. It does not necessarily seek, much less presume discoverable, an ultimate, solid ground out of which all levels may be derived.

The Kantian system in general argues that if any "ultimate principles" are to be discovered, as Ontology had assumed to be possible, such discovery will be only an outcome of the critical establishing and limiting of knowing, in and by experience. Following Hyppolite, nature and logos are viewed as self-establishing, correcting, and limiting. Given this framework, one might then view Kant's first Critique as an exploration of the nature-logos relationship with particular attention paid to the original cognitive situation. And here, we will find crucial the doctrines concerning limit and reciprocity, or negation and internal relation.

The first extensive treatment of these doctrines is found at the level of "relation" and the disjunctive judgment. It has community as its ever-present parailel 
in the table of categories. Kant has outlined all areas of relation as subsumed under those of predicate to subject, ground to consequence, and divided knowledge and the members of such division to each other. Whereas the first two types of relation seem to emphasize the re-union of externals, predicate to subject, ground to consequence, the third area emplnasizes the inter-relatedness of disjuncts to each other in a holistic community. That is to say, the components of the either-or "occup [y] a part of the sphere of the possible knowledge concerning the existence of a world in general; all of them together occupy the whole sphere." Inasmuch as the introduction of negation at the level of judgments of quality served to delineate the extension or exclusion of certain spheres of cognition given the worth or content of affirmation even through "a merely negative predicate," the disjunctive judgment seems to rely upon such exclusion but in order to seek out the community implied by the disjuncts:

There 1s, therefore, in a disjunctive judgment a certain community of the known constituents, such that they mutually exclude each other, and yet thereby determine in their totality the true knowledge."

Kant does not elaborate at this point the way in which the possible scope of disjuncts may "constitute the whole content of one given knowledge." Yet, in examining the level of judgments of modality one sees that the level of relation is, of a fashion, the apex of the table of judgments." For, in speaking of modality. Kant notes that its striking characteristic is that it "contributes nothing to the content of the judgment." He claims there to be nothing constitutive of content beyond quantity, quality, and relation. Ifere negation, as well as affirmation, is taken as possible, at the level of problematic judgment; in assertoric judgment it is taken as real; in apodeictic judgment it is taken as necessary. The fundamental status or role of negation, however, is not changed beyond its having been established at the levels of quality and relation.

Initially, one might have asked why negationlimitation appears in the second division of the table, is mentioned also in the fourth, but seems lacking in the third. It would appear that negative judgment is crucial at the level of quality and makes possible a de-limitation of the sphere of complete, unrestricted affirmation with its tendency toward infinite judgment. Negation functions as that setting-off of boundaries of judgment, making it possible to distinguish between various predicates. At the level of relation, Kant continues to rely implicitly on negation in the disjunctive judgment, again as de-limitation, but now with 
more primary emphasis upon the ability of the disjunctive judgment to outline or delimit a possible sphere by the totalizing of heretofore separated spheres represented by the disjuncts. Negation and its contribution are merely less "visible" in that the emphasis is to be placed on the possible community of disjuncts, which when totalized may yield a community of the knowable.

Kant explains the movement from the table of judgments to the table of categories in a discussion of the difference between general logic's procedure of analysis, bringing different representations under one concept and transcendental logic's bringing to concepts, not representations, but pure synthesis of representations. Three levels of givenness are outlined as necessary: the manifold of pure intuition, synthesis of this manifold by Imagination, and the concepts giving unity to this pure synthesis. Only these three together can yield knowledge. The linkage between judgments and categories is one of sameness of function.

The same understanding, through the same operations by which in concepts, by means of analytical unity, it produced the logical form of a judgment, also introduces a transcendental content into its representations, by means of the synthetic unity of the manifold in intuition in general.?

Such representations, the pure concepts of the understanding, are seen as applying a priori to objects and found at this level, heretofore unable to be discovered by general logic. Kant "finds" the same number and grouping of pure concepts of the understanding applied a priori to objects of intuition in general as had been discovered logical functions for all possible judgments. Thus appear in similar fashion: negation at the level of quality, community at the level of relation, with particular emphasis upon reciprocity of de-limited spheres (agent-patient), existence/nonexistence at the level of modality (these all being most cruclal to our enquiry).

Although Kant, in following out reason's critique in pursuit of a doctrine of method, does not see fit to provide exhaustive definitions of the categories, he does provide explication of crucial points concerning the table. Thus, he notes the organization of the levels of the table into groupings of three, emphasizing that each third category arises by combining each second one with the first. Hence, one may note the crucial role, contributed by negation in the broadest sense, of the second category of each division, providing a schism, de-limiting, or separation of the plenum of each first term. Each second category would appear to follow the general pattern of negation's role 
under "quality," putting differentiation at the heart of the first terms. This delimiting of a given sphere thus allows a possible knowledge and totalizing as manifest by each third term. This is most explicitly seen when taken up as "community" or "reciprocity" under "relation." Kant stresses the sense in which the third category of each level is as primary as, never derivative of, the other two:

For the combination of the first and second concepts, in order that the third may be produced, requires a special act of the understanding. which is not identical with that which is exercised in the case of the first and the second."

Here he pays attention to the co-ordination, not mere sub-ordination operative in the disjunctive judgment. Such co-ordination has been seen linked to the role of negation as establishing de-limited spheres such that the disjuncts are established in community with each other in their being-apart. Any idea of communityreciprocity for Kant thus upholds a particular sense of negation as de-limiting and specifies that the peculiar character of community-reciprocity is its being relation as internal relation.

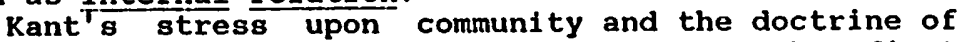
internal relations is to be found throughout the first Critique at various levels. However, his discussion concerning the third analogy of experience yields important insight into these doctrines. The third analogy pursues Kant's general attack on mere externality of relations and the affirmation of the critical role of community. The B edition version of the formulation of the analogy reflects a refinement or de-limiting of the scope of the claim of the analogy in the A edition. While earlier holding that "All substances, so far as they coexist, stand in thoroughgoing community, that is, in mutual interaction." Kant now moves from a more grandiose, ontologically tempting claim to the more modest, epistemological claim: "All substances, in so far as they can be perceived to coexist in space, are in thoroughgoing reciprocity." The doctrines of community and internal relations are present in both versions, showing Kant's ongoing concern for these views. Yet, it is crucial that the $B$ version evidences Kant's puliing back from the earlier temptation to claim ontological status for community. The change in the two versions reflects Kant's temptation by the ontological transgression whereby one says "Nature is logos." The $B$ version form of the third analogy affirms the growing up together, but mutual conflict and interaction, of nature and logos.

Kant's revised version of reciprocity, then, emphasizes its being a pure concept of the understanding, yielding possible synthetic a priori judgments. The 
critical role of reciprocity-community, however, is most clearly seen to be its capacity to provide us with a knowable world in a temporal context. In the discussion of the third analogy Kant notes that through empirical intuition, coexistence of things is possible given that the perceptions of them can follow reciprocally. The most basic element is that ". . . coexistence is the existence of the manifold in one and the same time." 10 A problem arises, however, in the impossibility of the perception of time itself and this is compounded by the apparent relation of things in the world as being merély externaliy related:

The synthesis of imagination in apprehension would only reveal that the one perception is in the subject when the other $1 \mathrm{~s}$ not there, and vice versa, but not that the objects are coexistent, that is, that if the one exists the other exists at the same time, and that it is only because they thus coexist that the perceptions are able to follow one another reciprocally.11

No empirical path alone could lead to anything but the perception, the discrete perception, of isolated objects.

Coexistence of substances in space is knowable only given the assumption of their reciprocal interaction. This is the condition of the possibility of the things themselves as objects of experience. ${ }^{12}$ Without such levels of coexistence and community, mere exclusionary relations would hold; no coherence spatially or temporally would be possible. One would be unable to account for the experience of the mantfold, the experience of objects as in ongoing relation and coexistence, and the relationship of a possible world of knowable objects and relations in their temporal context. One would be left with mere relations of externality, at all levels of experience--hence, without any true experience at all.

Having delineated the particularization of his general doctrines of community and internal relations in the discussion of rectprocity as a pure concept of the understanding, Kant ends the discussion of the third analogy with a note on the word "community" itself. He stresses that community has the dual significance of meaning communio or commercium. " He calls to our attention his use of community in the latter sense, stressing again the notion of relationships which are active and dynamic.

Community as local community could not even be possible without its grounding in community as commercium--1.e.. community as the dynamic introplay of internal relations. Furthermore, community as communio spatii would never be possible without its grounding in the more primary community as commercium which is in- 
tro-related with the generation of temporality via the perceiving subject. Kant has here returned to a revised version of the ontological claim merely asserted regarding the coextstence of objects in the world. The critical perspective, evidenced in the change from the $A$ to the $B$ editions of the Critique, now maintains a coexistence of possible objects of experience but via the dialectical introplay of time-space-perceiverobjects of experience, in an ongoing community of relations. The transcendental unity of apperception is now cast as relating us to a community of objects perceived-related not by merely exclusionary, isolated, truncated perceptions, but by the differentiatingcommunality of their commercium with an imaginative synthesis which generates with them the temporal context. Such an emergence of a dilactical relation of knower-known via their commercium through the generation of time and the organization of space leads to Kant's discovery of the dialectical introplay of subject-object, the creation of a world:

In our mind, all appearances, since they are contained in a possible experience, must stand in community (communio) of apperception, and in so far as the objects are to be represented as coexisting in connection with each other, they must mutualiy determine their position in one time, and thereby constitute a whole. If this subjective community is to rest on an objective ground, or is to hold of appearances as substances, the perception of the one must as ground make possible the perception of the other, and reversewise--in order that the succession which is always found in the perceptions, as apprehensions, may not be ascribed to the objects, and in order that, on the contrary, these objects may be represented as coexisting. But this is a reciprocal influence, that is, a real community. (commercium) of substances; without it the empirical relation of coexistence could not be met with in experiençe."

The import of the doctrine of community as commercio, community as differentiating and unifying, ūtimately yielding the dialectical character of the originary "word is nature" community, is borne out throughout the first Critique. However, Kant clarifies in the section on the Concepts of Reflection just how the introplay of community (communio) of apperception conjoined with real community (commercium) of substances yields up a holistic commercium of word and nature, concept and reality:

- . the principle that realities (as pure assertions) never logically conflict with each oth- 
er is an entirely true proposition as regards the relation of concepts, but has not the least meaning in regard either to nature or to anything in itself. ${ }^{25}$

Kant would seem to be claiming that the level of negation for mere concepts, abstracted from but not in relation to experience--the level of general logic--can be such that negation in such a realm remains bound to a doctrine of external relation. Contrary to this level, the levels of nature or experience demonstrate dynamic and conflictual community, de-limitation, and exclusion such that relation is internal and realities conflict, sometimes even annulling each other. Inasmuch as Kantian critique is to show the limits of possible experience in relation to reason, it is evident that it must concern itself with what is beyond the level of the mere relation of concepts. So, contrary to a doctrine which would affirm "all evils.. . [as] merely consequences of the limitations of created beings, that is, negations, since negations alone conflict with reality, "16 Kant proposes negation as more than merely privation or external, exclusive, exterior negation, and hence as the working of exclusion typified by delimitation of positive spheres--not the negation which portends the lack, the privation of an external nothingness. These remarks follow the thrust of the distribution and movement of the categorial and judgmental tables whereby internal relation, movement, and interdependency are preserved between the three terms of each level. A richer model, that of internal relation and conflict, is upheld rather than that of negation as privation.

This striking emphasis paid against "evils... [as] merely consequences of the limitations of created beings," that is against merely external "negations" in the section on Concepts of Reflection, is further clarified at the end of that section. Here Kant introduces, for the sake of completeness, along with the idea of inter-relation and in addition to the concept of an object in general, the concept of nothing. Interestingly, rather than provide the division of something, he introduces that of nothing, claiming that the former follows directly from it. Here we see most explicitly the sense in which negation is always relational, non-external, and is never an object. " Thus, as his allusion to a Leibnizian-Wolffian system makes evident, Kant rejects negation as privation, negation as an object, in the same way as he elsewhere rejects the ultimate intelifibility of a completed, totalized whole which would necessarily exceed our access to knowledge via experience. If negation is vitally linked to internal relation for Kant, it is because all knowledge and experience bear to each other reciprocaldelimiting, the commercio of conflictual relations. 
One succinct phrase, with which Kant concludes this section, seems to encapsulate the thrust of the Kantian work:

Negation and the mere form of intuition, in the absence of a something real, are not objects.'"

In opposing the claims of any Leibnizian-like model for plenitude which is totalized and accessible as a discrete whole to knowledge (and in a sense opposing in anticipation an Hegelian identity of nature-logos), Kant also opposes any similar claim for discrete, external negation. The concept of nothing in general must be viewed in its conflictual relation to the concept of something in general, always in relation to possible experience. Both concepts seem to be the outer, regulative edges of that which is central: community and reciprocity as the complexus of internal relations which conflictually limit and establish each other, an area accessible to human reason and experience. Thus at the heart of all critique of and by pure reason, at the center of Kant's entire enterprise, are the doctrines of negation internal to all experience, delimitation as relational, disjunction and commercio of community-reciprocity as a nexus of conflictual relations rather than separable and exclusive.

\section{I}

Our initial remarks about the Kantian system must now be kept in mind as we approach the place of reciprocity within the doctrine of essence in Hegel's Logic. We have shown how crucial the doctrines of negation, internal relation, and community-reciprocity seem to be for Kant. We have claimed that reciprocity especially as the "peale" of the third division "relation") of the table of categories is something like the apex of the table, the heart of the Kantian system. We have noted that perhaps Hegel has, in somewhat Kantian spirit, seen the richness of the category of reciprocity, making it the apex of the doctrine of essence. Yet, as the Logic of 1830 notes, we must be cautious and reassess the Hegelian reappropriation of "reciprocity" :

Reciprocity is undoubtedly the proximate truth of the relation of cause and effect, and stands, so to say, on the threshold of the notion; but on that very ground, supposing that our aim is a thoroughly comprehensive idea, we should not rest content with applying this relation. If we get no further than studying a given content under the point of view of reciprocity, we are taking up an attitude which leaves matters utterly incomprehensible. We are left with a mere dry 
fact; and the call for mediation, which is the chief motive in applying the relation of causality, is still unanswered. 19

These remarks lead us to see that Hegel's appropriation of reciprocity has a place in the system but only as a transition into the development of the notion. Reciprocity remains merely a point of view, a partialized access, a way of studying a given content. Hegel capitalizes on the restricted sense or context of reciprocity as the mere fact of community of agent-patient, outgrowths of the mere "facts" of cause and effect. As such, his observations on and use of reciprocity seem to ignore its more radical functioning as contributing to the type of doctrines we have alluded to earlier-those of the complexus of reciprocal internal relations having a vital sense of negation and limit at their center. Such doctrines attempt, by being present and crucial for the table of judgments and categories, to achieve articulate unification as the self-limiting difference of nature-logos.

Hegel has certainly not read Kant this way and takes reciprocity, at best, as a partialization which leads into the notion, which "alone" can achieve the level of the true. It is not at all surprising that Hegel's treatment of reciprocity would seize upon its seemingly limited or weaker usage in Kant--that pertaining to cause and effect and the community of agentpatient--hence, ignoring the broader, stronger roles we have suggested for it above. Taking reciprocity in 1 ts limited, weaker sense, Hegel may then easily see it as a mere external relation of two "sides" resting "in their state of mere given facts," evoking a call for mediation; as factors, the "sides" evidence the need for a "third and higher" factor. "whichis the notion and nothing else."in such a treatment of reciprocity should not surprise us, if we recall its placement at the "apex" of, but nonetheless within, the doctrine of essence. We recall with Hegel:

The terms in Esgence are always mere pairs of correlatives, and not yet absolutely reflected in themselves: hence in essence the actual unity of the notion is not realized, but only postulated by reflection. 22

Reciprocity and all other terms in the doctrine of essence, can have no vital sense central to the relationship of nature-logos. That is to say that it cannot take on the status of a primary doctrine of internal relation for Hegel as we had suggested it assumes for Kant. This is the case in that nowhere in "essence" is the actual unity of the notion realized; it is only postulated by reflection. We must explore further the way in which Hegel "finds" reciprocity situ- 
ated in essence so as to understand his treatment of it, thus constituting his radical divergence from Kant.

Because reciprocity is found, for Hegel, within the doctrine of essence, we must recall what Hegel's claim means--that the truth of Being is essence. The initial remarks of the second book have reiterated the sense in which Being is the immediate. As such, and because knowing will not stop short of becoming knowledge of what Being is in and for itself, knowledge penetrates Being. Hegel indicates here that movement beyond the immediacy of Being is one of inwardization, of recollection. Knowing recollects itself out of immediate being; through such mediation essence and all its categories, including reriprocity, are found. ${ }^{2}$ Here Hegel capitalizes upon his natural language's use of the past participle of "to be" to express essence. Essence (as gewesen) is past--as timelessly past--being. His use of the past participle in this way would seem to attribute to essence a certain persistence, the state of its being-non-temporally. If originally, then, the absolute was taken as Being, such a stance of immediacy was a-temporal but without the character of any effectivenesg for cognition as that which can be appropriated. The movement of cognition, however, encounters essence as equally a-temporal, but now as a state of the persistence of Being as recollected and inwardized.

Hegel notes that cognition "cannot stop short at manifold determinate being, nor yet at being, pure being." "2" Reflection, he says, forces itself on the scene, showing that pure being, as the negation of all that is finite, presupposes internalization, recollection, and movement which have purified and transformed immediate determinate being into pure being. We thus see Being determined as essence, where everything determinate and finite is negated. We must note already, even in such a general context as this, that reciprocity will be situated at the peak of a grouping of categories which involve and express utter negation of all that is determinate and finite. That this implies a radical divergence from Kant's use of reciprocity must be clarified further. Already in these opening passages which introduce us to the doctrine of essence, we begin to see some major aspects of this divergence:

We have already mentioned that if essence is defined as the sum total of all realities, then these realities likewise are subordinate to the nature of the determinateness and to the abstractive reflection and this sum total reduces to empty oneness. ${ }^{25}$

In the last analysis, the more comprehensive and comprehensible statis of essence will be its emptiness as well. For it remains prisoner of the levels of 
givenness upon which it relies, out of which its inwardization has achieved a higher but, as yet, still. inadeguate level of knowledge; it remains dependent upon the "nature" of determinateness and upon abstractive reflection. At the level of essence, for Hegel, these are conjoined, but externally and without internal articulation. Summarizing what will be developed at greater length as the crucial difference between the doctrines of essence and notion. Hegel points to that which seems most crucial for our enquiry concerning reciprocity.

. . the Notion is the absolute that in its determinate being is absolute, or is in and for itself. But the determinate being which essence gives itself is not yet determinate being as in and for itself, but as given by essence to itself, or as posited, and is consequently still distinct from the determinate being of the Notion. 26

To the degree that reciprocity falls within the domain of the doctrine of essence it can never, of itself alone, achieve the status it held for Kant. It remains at best, as Hegel puts $1 t$, at the level of product or artifact. ${ }^{27}$ This is the case in that the categories of essence are only levels of givenness by essence to itself and not those of determinateness as in and for themselves. What might then be taken as the dynamism of the Kantian doctrines of reciprocity, a dynamism combining the movement of limitation-negation with internal relatedness, remains for Hegel as the static formalism which attempts to cement the categorlal format to the manifold of sense. Both are given for Kant, only to be united in a knowing subject. For Hegel such levels of mere givenness, only coherent unto themselves, remain external. Again, as we have earlier noted, for Hegel only the movement of the Notion, beyond essence, can overcome the alleged externality of such levels of givenness which he takes Kant to have accepted "blindly." Essence, and reciprocity within it, at best remains only a level of positedness, of givenness, for cognition.

The third section of the division on the doctrine of essence, entitled "Actuality." bears out these general remarks, but directing our attention, while following the categorial expositions, to a moxe specific sense of reciprocity's place within the doctrine of essence. For Hegel, the movement toward the Notion must pass through and beyond exposition to selfexposition. Such a move into the level of the true notional movement occurs, passing through actuality. Actuality is the unification of essence and existence, the place where formless essence and unstable appearance achieve their truth. The movement is that of 
reflection-into-an-other into reflection-into-self, becoming two worlds, two totalities of content. Essential relation, however, shows the "form relation" of the two, culminating in the relation of inner and outer such that the two "contents" of the two worlds are seen to be identical. The determinations of form, here, are then posited as one absolute totality. ${ }^{28}$

The first two-thirds of the doctrine of essence, then, have built up to the relation of inner and outer, culminating in their unity as absolute actuality. Again, however, the problem recurs that such actuality, as the absolute as such, is a posited unity to which reflection bears external relation. Reflection merely contemplates the absolute here rather than being the absolute's own movement. Hegel notes that the "simple substantial identity" of the absolute, the unification of essence and existence, here leads into a dissolution. "Accordingly, the process of determining what the absolute is has a negative outcome, and the $a b-$ solute itself appears only as the negation of all predicates and as the void." 2 "Yet such negation as the "position" of all predicates generates, as well, a formal contradiction. Hegel is quick to note that such a negating-positing has to do with external reflection and a formal and unsystematic dialectic. For such a dialectic, casually emphasizing certain determinations and not others, seemingly arbitrarily, it is possible only to take determinations in their isolated finitucle and mere relativity to each other, yet as well thinking vaguely of the absolute as the totality of determinations. Such determinations are somehow immanent in the totality, yet the positions-negations of the determinations cannot be raised to a level of genuine unity.

It is thus seen necessary to demonstrate the absolute, but neither as a determining nor external reflection. It is necessary not only to achieve exposition but also to follow the self-exposition of the absolute and what it is. Even at this point, one might interpolate the Hegelian criticisms of Kant and his use of or development of the categorial format. Even what might be the Kantian claim for the internal coherence and relatedness of the categorial arrangement, Hegel criticizes as, at best, a formal and ultimately contradictory arrangement of the negation and positioning of predicates. Hegel sees such a system as emphasizing a merely finite, relative range of predicates with only a vague sense for the absolute as the totality of determinations within it. It proposes no true sense of unity and cannot achieve an exposition, much less the self-exposition, of the absolute.

If Hegel then were addressing these remarks to the specific status of the categorial arrangement offered by Kant, his criticism would seem twofold: First, that Kant has not adequately developed at the level of each of the four major divisions of the categories (or of 
the judgments) a vital movement among each of the three terms. He has only achieved the type of positionnegation which eventuates in formal contradiction, not the special status of each third term which Kant claims. Secondly, from these remarks throughout "essence," Hegel would seem to imply that anything like the Kantian categorial structure is not a true exposition of the absolute, because unable to show its movement from one level of category to another. Moreover, because it cannot even achieve a dynamic movement ox articulation of relation between levels of categories as exposition or movement, it certainly does not approximate the status of any self-exposition. For Hegel, Kant has moved beyond the externality of relations of the categories of merely formal, traditional logic: yet, his achievement of the categories of a transcendental logic only complicates the traditional logic's formalism by adding another level of emptiness. The determinations available through the categorles, as negation and positing, eventuate in formal contradiction; the inability of the table of categories to become a self-exposition of absolute relationship reflects its basis in formal and unsystematic dialectic. Only the vague indication of the absolute takes the place of a true self-exposition which the necessary development and movement of the absolute demands.

of course the inability of the Kantian system to achieve such a self-exposition derives from its refusal of the very standpoint to and from which the Hegelian system, and the development of the doctrine of essence moves--the absolute and the doctrine of the Notion. To the degree that our remarks or projected criticism by Hegel against the Kantian categorial system might be appropriate, we should be able to find more specific corroboration in Hegel's treatment of reciprocity. since it will serve as a bridge over into the doctrine of the Notion.

Hegel's rearrangement and reappropriation of the fourth division of Kant's categories led him to develop necessity into absolute necessity--"being, simply and solely as reflection." This is the relation, a distinguishing whose elements subsist as its whole totality; there is only one subsistence and any difference is only the reflective movement of the process of exposition. Essence is exposed as illusory showing. But the achievement of illusory being posited as illusory being leaves no residue, rather it is absolute actuality. The absolute, although originally taken up through external reflection, now achieves self-positing.

Such self-positing shows forth the self-determining of the aspects of the absolute relation, beyond the level of such aspects merely as attributes. Such a relation, as to its immediate notion, is that of substance and accidents. Yet, this is only the movement 
of "absolute illusory being" in itself. Determination of substance achieving "being-for-self over against an other" has been shown as the absolute relation determining itself as real." This is the relation of causality. When such a self-relating achieves a unity with its determinations, positing the absolute relation in accordance with them, reciprocity is attained. Such a posited unity, of self-relating and determinations as the whole, alone allows the achieving of the notion.

This, the culminating achievement of the doctrine of essence is reciprocity, and the bridge over into the Notion. Here Hegel recalls that in finite causality substances are actively related to each other. Mechanism is this externality of causality such that the effectiveness of causality as its reflection into itself is, as well, its resistance:

- . In the self-identity which the causal substance has in its effect, the cause equally remains something immediately external to it, and the effect has passed over into another substance. 32

The achievement of reciprocity is the sublation of this mechanistic movement, the surpassing of its mere externality. For reciprocity is the "vanishing" of that persistence, here as immediate substantiality, with which we recall Hegel first "undertook" essence. Being, as essence, has traversed the range of its "state" as timelessly past being (gewesen). As having undergone its own self-exposition as something of a turn into but now recoiling from its formal emptiness, it has achieved the level of the "coming-to-be of the cause and hence originativeness as self-mediating through its negation. "Js Here we must note that this sense of originativess as reciprocity is crucial to Kantian doctrine in a special way which precludes the (Hegelian) necessity of any move to a more absolute standpoint. Reciprocity in this sense remains the apex of Kant's system.

But here, quite differently than Kant, Hegel pursues reciprocity as causality of presupposed, selfconditioning substances which, since each is both active and passive in relation to each other, obliterate any real distinction between them; this leaves any socalled reciprocity between them to be an empty formulation. What is required, says Hegel, is an "external bringing together of what is already both in itself and posited." Yet, since no longer substrates but rather substances are considered here in their relation to each other, what initially appeared as external mediation is truly a self-mediation. This is so to the degree that the presupposed immediacy has been sublated and "the conditioning factor of the causal activity is still only the passivity of being acted upon, or the 
passivity of the cause itself." 3 " This achievement is causality--as conditioned and conditioning. Reciprocity is then causality itself and has returned to its absolute notion.

Hegel sees here that a further move has been accomplished, in claiming that the Notion itself has been attained. The level of substances involved a) free actualities against each other and b) necessity, taken as inner identity. Yet, causality, with its "illusory show of substantial otherness" having been sublated, accomplishes freedom out of necessity:

In reciprocity, originative causality displays itself as an arising from its negation, from passivity, and as a passing away into the same, as a becoming . . . 35

The tension of such an originative causality with negation, however, is in turn, as becoming, seen to be illusory. For in typical Hegelian fashion the alleged transition into otherness is a reflection into seif, "the negation, which is ground of the cause, is its positive union with itself."37

With reciprocity, necessity and causality have vanished. The "result" is the absolute contradiction of a) immediate identity, as relation, of the different "sides" and b) the absolute substantial status of the different "sides." Necessity. Hegel claims here, is Being just because it is a unity of being with itself, having itself for ground; but having its own ground it cannot fully be Being. And so illusory being, mere relation or mediation, is the true status discovered. Causality is this not self-sustaining but merely posited as the transition of "originative being" (cause) into "illusory being" (positedness) and positedness into originativeness. The and here bespeaks an identity of being and illusory being which sublates causality. makes substantiality vanish, and reveals necessity. Ereedom does not arrive on the scene due to the vanishing of necessity; rather it arises as a result of the manifestation of the inner identity of necessity--that of being and illusory being. Contingency becomes freedom once the "sides" of necessity, first appearing as independent, free actualities which are discretely self-sustaining, are posited as an identity.

- . these totalities of reflection-into-self in their difference are now also reflected as identical, or are posited as only one and the same refiection."

A level of absolute substance is thus presumed achieved which self-differentiates as universal because originative; as well it self-differentiates as individual because of its negative aspect as self-identical 
determinateness, positing itself as the whole as selfidentical negativity:

This their simple identity is particularity. which contains in immediate unity the moment of determinateness of the individual and the moment of reflection-into-self of the universal."

Hegel claims here that the three "levels" considered are one and the same reflection; but as negative self-relation, typical of all levels in the doctrine of essence, they merge into a "perfectly transparent difference." He calls this determinate simplicity, simple determinateness--the level of identity which is the Notion--the "realm of subjectivity or of freedom."

We have followed Hegel' $\mathrm{g}$ discussion thus far, but will not plunge further into the doctrine of the Notion. Yet, our excursus with Hegel to this point has provided an adequate basis for seeing to what degree his treatment of reciprocity is radically different from that of Kant. What we have just seen Hegel term "determinate simplicity," the level of identity which is the Notion, seems to be the mere fact or relation of reciprocity of which he speaks in the Logic of 1830 . Yet, the mere fact of reciprocity, reciprocity as an externality, a mere point of view available to cognition, is just that only to the degree that it does not penetrate the "realm of subjectivity or of freedom." The fact of reciprocity then is the level achieved by the three totalities--individuality, universality, and particularity--as transparent difference. But it remains mere fact if not imbued with the life of the Notion, if not comprehended in the province of subjectivity and freedom. Staying within the province of essence, these totalities are merely empty terms. Hence, the level of reciprocity, unto itself, must yield to the Notion, be absorbed by it, and cede to it any original tension or originative power it might first appear to have.

In conclusion, we wish to recall our earlier considerations of Kant's use of reciprocity, now adding to our claims those insights which are available as a result of seeing how Hegelian "reciprocity" has collapsed or yielded to the Notion. Since our earlier remarks about kant remain heavily weighted on the side of Kant's development of reciprocity more strictly in the province of the categorial arrangement and the discussion of community as commercium, we must expand these remarks to approximate a comparabie level which Hegel's treatment has approached--that of subjectivity and freedom. Ultimately, we wish to argue that Kant, via reciprocity as a strong, very broadly based and farreaching doctrine (not only in its limited, categorial use), has achieved the articulation of the nature/logos relationship as a vital tension, a creative locus 
which, for Hegel, and because of his use of reciprocity, collapses, thus eventuating in the need for the move to the Notion and the absolute standpoint.

Hegel has introduced reciprocity as "originativeness as self-mediating through its negation," and done this via a discussion of causality as conditioned and conditioning. His treatment of these however has claimed to discover their movements to eventuate either in vanishing, the collapsing of term upon term or in absolute contradiction. For Kant, however, it would appear that the tension of such "finds," which for Hegel is not maintained but rather impels movement to a higher level of stability, is the locus of subjectivity and freedom. We have earlier outlined the formal sense in which reciprocity/negation is the tension and dynamism of internal relations for Kant. His claims for the status of subjectivity, involving both theoretical and practical reason, and freedom seem to be undergirded by the very creative tension which a doctrine of reciprocity offers. For the entire activity of lknowing and experience is the relationship grounded in the fragile tension of an "originativeness as self-mediating through its negation"--the originary but transparent status of human subjectivity as the transcendental unity of apperception. Equally important, because always the same subjectivity, the free activity of the subject as both obligated and self-legislating will is rooted in such a notion of reciprocity. Here what Hegel has discovered as the conditioned-conditioning relationship (eventually found inadequate and hence generating the need to seek freedom-subjectivity elsewhere, in the Notion), Kant claims to be subjectivity as the fragile tension of the finite rational being who is both intelligible and intelligible-sensible; free from natural necessity and free toward the selfiimiting within and creating of the sensible, the contingent. The formal paradigm of reciprocity as the conflictual tension, the creative center of negation/internal relations, is the very life of human subjectivity both as the spontaneous activity of theoretical reason and as the free, autonomous, self-legislative activity of practical reason. Reciprocity, even for Kant, would remain a mere fact, an empty relation, were it not for its being, as a formal structure, derivative of its life-contextualizing force. This is to claim that the Hegelian reading of a Kantian formal reciprocity would be correct only if the structural paradigm is cut off from its life-relation to human subjectivity and freedom. Not seeing such a connection available in the Kantian system, Hegel does need a movement onward to the Notion, if any sense of subjectivity-freedom is to be discovered and explicated.

A further development of those claims would be necessary to fill in the material with which Kant makes the connection between the "formal" levels of reciproc- 
ity, theoretical reason, and practical reason. They are most readily available, however, in his discussions of the keystone concept of freedom, the primacy of practical reason, the treatment of is/ought, and especially the delineation of the tension which is human subjectivity as intelligible/intelligible-sensible (not merely intelligible/sensible). Such discussions point us closer to seeing his ciaims for human subjectivity as an active reciprocity.

The suggested contrasts appear at least helpful toward a better understanding of the very dense and dark exposition of Hegel's doctrine of essence. Reciprocity as the culminating category in this division of the Logic may serve as the guiding thread back through the materials considered before its appearance. The inadequacy of reciprocity for Hegel, contrasted with its apparent centrality for Kant, may help us better understand the sense in which Being as indeterminate is our beginning in the Logic but found not effective (unwirklich), distant from activity, much less human activity. Essence and its ultimate self-exposition of categories, as a level of mediation of correlative but "empty" terms, is effective but empty because it is still the givenness of determinations and the positing of abstractive reflection. For Hegel, the redeeming grace of essence, though, is to be found in reciprocity. which as the mere sum total of determinations nonetheless has achieved the complete state where no external residue is outstanding. Such a formal completeness awaits the Notion and relation with subjectivity and freedom. The quite different Kantian treatment of givenness and activity, as the central doctrine of reciprocity which is free, rational subjectivity (not merely a formal categorial structure), may serve as a corrective or at least clarifactory measure so as to understand eventually to what degree the movement into the Notion, like the status of reciprocity for Hegel, will or will not eventuate in total collapse--that of logos-nature upon each other--and the vanishing of any true, free human subjectivity.

\section{NOTES}

Immanuel Kant, Critique of Pure Reason, trans. Norman Kemp Smith (New York: st. Martin's Press. 1965). A86/B118 (emphasis added) .

${ }^{2}$ Ibid., B1. 
JJean Hyppolite, Logique et Existence (Paris: Presses Universitaires de France, 1953), p. 130. My translation of:

On ne doit donc pas dire le Logos et la Nature, mais le Logos est la Nature, la Nature est le Logos. Le jugement (Urteil) énonce la division originaire, 11 est 1 'identite relative, la mediation encore immédiate. C'est seulemant le raisonnement, la miédiation, qui développe le caractère dialectique de ce est, en montrant à la fois 1 'opposition des termes, leur contradiction, et leur identité. Le raisonnement seul fait apparaitre l'esprit dans le Logos et dans la Nature.

"Kant, B99.

Ibid.

"We would get ahead of ourselves to argue this here, but might note that finding such an apex in the third, not fourth, level of both tables (of judgment and concept) gives Hegel good Kantian ground for "reversing" the order of levels III and IV in his treatment of categories in the Logic.

'Kant, B105.

ibid., B111.

'Ibid. 'B256 and A211.

${ }^{10}$ Ibid. B257.

11 Ibid.

12 Ibid.. B258.

${ }^{13}$ Ibid. , B260.

1"Ibid., B261.

1 Ibid. , B328-329.

16 Ibid. B329.

17Ibid., B349.

18 Ibid.

"Hegel's Logic, Encyclopaedia of the Philosophical Sciences part one (1830), trans. Wilitam Wallace (Oxford: clarendon Press, 1978), p. 219 (paragraph 156). 
20 Ibid.

2 Ibid.

${ }^{22}$ Ibid., p. 162 (paragraph \#112).

2'Hegel, Science of Logic, trans. A. V. Miller (New York: Humanities Press, 1976), p. 389.

2 "Ibid.

${ }^{25}$ Ibid., pp. 389-90.

26 Ibid. , p. 391.

27 Ibid. . p. 390

20Ibid. , p. 529 .

${ }^{29}$ Ibid. , p. 530 .

${ }^{30}$ Ibid., p. 554 .

"I bid.

32 Ibid. , p. 569.

"Ibid.

"Ibid.

${ }^{35}$ Ibid. , p. 570 .

"Ibid.

37 Ibid.

"Ibid., p. 571

"Ibid. 